$$
\begin{gathered}
\text { Érica de Cássia Ferraz } \\
\text { Pesquisadora autônoma } \\
\text { https://orcid.org/0000-0003-0272-8604 }
\end{gathered}
$$

\author{
Ana Luiza Navas \\ Faculdade de Ciências Médicas da Santa Casa de São Paulo \\ http://orcid.org/0000-0003-3677-6401
}

\title{
MANUSCRIPT SUBMISSION AND EVALUATION: JOURNAL CHARACTERIZATION AND EDITOR'S PERCEPTION
}

https://doi.org/10.21452/procpc 10

\footnotetext{
Dissertação apresentada como parte dos requisitos para certificação no CSE Publication Certificate Program
}

São Paulo (SP) 


\title{
Manuscript Submission and Evaluation: Journal Characterization and Editor's Perception
}

\begin{abstract}
Scientific journals have a great geographic reach and are used for reporting research, intended to the progress of science. As well as the research, the quality and reliability of journals should be also considered. The scientific community follows guidelines, codes of conduct in research and best practices to support its activities. Since the level of demand of quality scientific journals is constantly increasing, the editor plays a fundamental role in this scenario. Thus, this work will show the importance of the editor's management for the quality of the journal.
\end{abstract}

Keywords: editor management; best practices; codes of conduct in research; guidelines; ethics.

\section{1) Introduction}

Scientific journals are vehicles of diffusion of knowledge. They have a great geographic reach and are used for reporting research, intended to the progress of science. Additionally to the research, the quality and reliability of journals should also be considered. Journals that publish meaningless articles, produced by software that combines word sequences in a random manner are recurrent. Other journals, without credibility, publish manuscripts without going through a peer review process, or only upon payment of publication fees. These situations are, obviously, condemned by the scientific community that follows strict guidelines, codes of conduct in research and best practices to support its activities, as the CSE White Paper and the COPE guidance.

The level of demand of quality scientific journals is constantly increasing and the editor plays a fundamental role in this scenario. Thus, the goal of this project is to characterize the profile of some scientific journals in regards to the submission and evaluation of manuscripts process and to describe the perception and the conduct of the editor in the management of the journal. The study is descriptive and the idea is to illustrate the editors' point of view in terms of strengths and weaknesses, to promote reflection and possible improvement in the quality of scientific journals.

\section{2) Methods}

\subsection{Ethical Aspects}

The project was submitted to the Research Ethics Committee of the Irmandade da Santa Casa de São Paulo and approved under opinion 470.373, CAEE 23608813.8.0000.5479. To comply with the ethical precepts for research with human beings, a Participant Information Letter and an Informed Consent Form were prepared. The document was read and accepted by the participants.

\subsection{Procedures and Instruments}

A questionnaire was developed by the authors and it consists of 26 multiple-choice questions divided into the following themes: 

A. Editor profile
B. Journal characterization
C. The reviewers
D. The authors
E. The manuscripts evaluation
F. Improvements for the journals

The questionnaire was sent (and answered) online, in an anonymous way, to 70 scientific journal editors of Audiology and Speech Language Pathology and related areas. The journals were selected from brazilian and international databases and the criteria for inclusion was to publish manuscripts in Portuguese and/or English language. Five Brazilian editors and 11 from other countries answered the questionnaire (Table 1).

Table 1. Participants invited and who responded the questionnaire

\begin{tabular}{|l|c|c|}
\hline Editors & Invited & Answers \\
\hline From Brazil & 15 & 5 \\
\hline From other countries & 55 & 11 \\
\hline Total & 70 & 16 \\
\hline
\end{tabular}

\section{3) Results}

\section{A. Editor profile}

Most of the respondents hold the position of Editor-in-Chief or Scientific Editor and have held this position for more than five years. Only one respondent is an assistant editor.

\section{B. Journal characterization}

Educational institutions are responsible for $60 \%$ of Brazilian journals, and private publishers for $50 \%$ of other countries journals. $60 \%$ of the Brazilian journals do not have any funding or sponsorships and more than $50 \%$ of other countries journals have some kind of financial support. For $100 \%$ of the Brazilian journals and for $90 \%$ of other countries journals, the publishing costs are charged to the authors.

More than $70 \%$ of journals follow a code of conduct and best practices in scholarly research. Three editors answered that their journal does not follow any kind of guidelines and one was not sure.

The majority of Brazilian journals receive between 200 and 250 manuscripts per year and for the journals from other countries between 50 and 100 manuscripts. Regarding the annual average of journal citations, the responses were not coincident. Most editors were not sure about this answer.

The average annual rate of manuscripts rejection is between $20 \%$ and $30 \%$ for $80 \%$ of the Brazilian journals and of $50 \%$ and $60 \%$ for the majority of the other countries journals. The average time for a manuscript approval is between 6 and 9 months for $40 \%$ of the Brazilian journals. For $45 \%$ of the other countries, the average is between 3 and 6 months for $45 \%$ of the 
journals and between 6 and 9 months for $45 \%$ of them. The manuscript publication (considering ahead of print) average varies between 3 and 6 months or between 6 and 9 months for the Brazilian journals. For the other countries journals, it is between 6 and 9 months for $36 \%$ and less than 1 month for $27 \%$ of the journals.

\section{The reviewers}

The primarily selection criteria for members of the Brazilian editorial board is to own a PhD degree, and for the other countries' journals is being an expert. Being recognized in the area is the second most common answer for both.

For most of the Brazilian journals, the manuscript analysis form has open questions and for the other countries it is a free form, without script. Two reviewers analyze the manuscript for the majority of the Brazilian and other countries journals; on average they have 30 days to state their opinions and $60 \%$ mostly meet the deadline. Considering the reviewers that usually do not meet the deadline, the editor approach is to call the reviewer and set a new deadline.

In regards to the main difficulties that editors have with the reviewers, conflict of interests and professional qualification are the items considered of small difficulty, but manuscripts overload is a very difficult situation for the Brazilian editors. Unavailability and lack of response are the very difficult situations for the editors outside Brazil.

For the Brazilian editors, making the review turnaround time longer could improve the performance of reviewers since the number of experts in some specific areas are limited and they would have more time to dedicate themselves to each review. For the editors from other countries, including young researchers in the editorial board or as ad hocs reviewers would be of great relevance.

When asked what are the characteristics of a bad review, all of the editors answered "lack of criticism". Most Brazilian editors also mentioned "request different reviews every new round" and the editors of other countries also answered "lack of suggestions for specific changes in the manuscript".

\section{The authors}

In more than a half of the journals the authors may suggest a reviewer to analyze (or not) their manuscript and, in general, the author's receptivity is good in regards to the reviews. The Brazilian authors sometimes contest the reviews and rarely it happens with authors from other countries. However, $20 \%$ of the Brazilian editors answered that the reviews are considered "personal" by the authors when they receive criticisms.

\section{E. The manuscripts evaluation}

The manuscript evaluations process is anonymized for authors, reviewers and associate editors in most of Brazilian journals, and only for authors and reviewers from other countries journals.

Problems with text editing (spelling/grammar) are an uncommon cause of manuscript rejection for the editors outside brazil and the very common cause is being inadequate for the journal's scope. The Brazilian editors do not have a consistent response for this question. 


\section{F. Improvement for the journals}

When asked to the editors what they think that could enhance the editorial process of their journal, the options were: a) Exchange of experience between editors of other journals in the field; b) Encourage collaboration of authors and reviewers from other countries; c) Promote specific events on scientific writing, with partnership between the journals; d) Disseminate the journal's goals, actions and achievements, periodically; e) Increase the journal's exposure in social media; f) Standardize certain requirements between the journals (eg, manuscript format, deadlines etc.).

The two answers' option that all the Brazilian editors said would improve the editorial process a lot are: encourage collaboration of authors and reviewers from other countries and increase the journal's exposure in social media. However, the editors of other countries do not have a consistent answer. Most of them consider that the presented options are indifferent or would slightly improve the journal.

\section{4) Discussion}

Based on the questionnaire responses we could see a general panorama of some Audiology and Speech Language Pathology and related areas journals. It was a very good notice to realize that more than $70 \%$ of the journals (Brazilians and from other countries) follow a code of conduct or best practices guidelines in scholarly research.

According to the Council of Science Editors (CSE), considering the differences between the areas, the intention of the White Paper on Promoting Integrity in Scientific Journal Publications is to inform and guide rather than to direct. In the same way, the Committee on Publication Ethics (COPE) developed the Code of Conduct and Best Practices Guidelines for Journal Editors, expecting their members to adhere to the Code of Conduct whereas the Best Practice is more aspirational and voluntary, but advisable.

There are some differences between handling a journal in Brazil and in other countries, which can be demonstrated by the kind of responsible institution for publishing the journal and by the funding or sponsorship resources. Each of them probably have different challenges but it does not mean that one of them is right or wrong. Considering the time on the position, the consulted editors can be considered experienced, and probably with a development strategy for the journal.

Surprisingly, the Brazilian journals receive more manuscripts per year than the other countries. However, the Brazilian average annual rate of rejection of manuscripts is lower than the other countries. So, this is something to be better investigated since they are some quality indicators.

The manuscript analysis is similar for the editors of all the respondent countries, in terms of review form, number of reviewers and time for review.

The manuscript approval and publication time are also similar between journals but some editors outside Brazil said that their manuscript publication average is less than one month. This is a very short time considering all the production stages, and the journal team has to be very well organized and punctual to achieve it. 
There are also similarities and differences not only in terms of the journal characteristics, but also of managing authors and reviewer's issues. The consulted editors have the same opinion regarding the difficulties with the reviewer, of how to handle when the reviewer does not meet the deadline and of what is a bad review. This last item was a unanimous response, showing that they are all aligned, even those that said don't follow any guideline or best practices conduct.

On the other hand, the editors' responses diverged about what could improve the reviewer's performance and the editorial process. The main selection criteria for members of the editorial board is also different. The academic title is very well appreciated in Brazil and we may have a cultural difference here. Manuscripts overload and unavailability or lack of response are the very difficult situations for all the editors.

Handling all of these kinds of situations, as well as the author's behavior when receiving a critical review are some of the expected editor's competencies and they can be supported by documents as the mentioned CSE White Paper and on COPE Code of Conduct and Best Practices Guidelines.

\section{5) Final Considerations}

By the editors' responses we can infer that they are updated in regards to Code of Conduct and Best Practices Guidelines for Journal Editors. They are also aware of their rights and responsibilities, as well as engaged and committed to promoting integrity in scholarly research and its publication. The editor's management is essential for the quality of the journal.

\section{6) References}

- Albuquerque UP. A qualidade das publicações científicas - considerações de um editor de área ao final do mandato [opinião]. Acta Bot Bras. 2009;23(1):292-6. [accessed on: April 10, 2021]. Available at: http://www.scielo.br/pdf/abb/v23n1/v23n1a31.pdf

- Cáceres AM, Gândara JP, Puglisi ML. Redação científica e a qualidade dos artigos: em busca de maior impacto. J Soc Bras Fonoaudiol. 2011;23(4):401-6.

- Committee on publication ethics (COPE). Code of conduct and best practice - guidelines for journal editors. Committee on publication ethics; 2011. [accessed on: April 10, 2021]. Available at: http://publicationethics.org/files/Code of conduct for journal editors Mar11.pdf

- Editorial Policy Committee, Council of Science Editors. CSE's White Paper on Promoting Integrity in Scientific Journal Publications. Wheat Ridge, CO: 2018. [accessed on: April 10, 2021]. Available at: https://www.councilscienceeditors.org/wp-content/uploads/CSE-WhitePaper 2018-update-050618.pdf

- Fundação de Amparo à Pesquisa do Estado de São Paulo (FAPESP). Código de boas práticas Científicas. FAPESP; 2014. [accessed on: April 10; 2021]. Available at: http://www.fapesp.br/boaspraticas/FAPESPCodigo de Boas Praticas Cientificas 2014.pdf

- ICMJE (International Committee of Medical Journal Editors) uniform requirements for manuscripts submitted to biomedical journals. International Committee of Medical Journal 
Editors; 2019. [accessed on: April 10, 2021]. Available at:

http://www.icmje.org/urm main.html

- Packer AL. Os periódicos brasileiros e a comunicação da pesquisa nacional. Revista USP. 2011;89:26-61.

\section{Sources}

- Bueno WC. Comunicação científica e divulgação científica: aproximações e rupturas conceituais. Inf. Inf. 2010;15(n espec):1-12.

- Chagas ATR. O questionário na pesquisa científica. Administração On Line. 2000;1-

1. [acessed on: April 10, 2021]. Available

at: https://moodle.ufsc.br/pluginfile.php/1255609/mod resource/content/0/O questionarion

a pesquisacientifica.pdf

- Marlow MA. Writing scientific article like a native English speaker: top ten tips for Portuguese speakers. [Editorial]. Clinics. 2014;69(3):153-7. 
